\title{
Potential Fungal Control of the Subterranean Termite Heterotermes indicola (Wasmann)
}

\author{
Ayesha Aihetasham, Saira Shariq and Javed Iqbal Qazi* \\ Department of Zoology, University of the Punjab, Lahore 54590
}

\begin{abstract}
A B S T R A C T
This study was conducted for isolation and identification of fungal species from cadavers of notorious subterranean termite, Heterotermes indicola. Virulence of Rhizopus stolonifer isolate and resultant variations in food consumption of $H$. indicola workers were evaluated over a period of one month by employing surface culture method. Following different time exposures, $R$. stolonifer significantly produced epozootics on the tested insects, with resultant decrease in food consumption. Behavioral changes included lethargic workers which were observed even being eaten up by other workers. These experiments revealed that $R$. stolonifer is a potent biological control agent against $H$. indicola. Scaleable cultivation of this fungal species and its application for controlling the termite under select situation need further investigation.
\end{abstract}
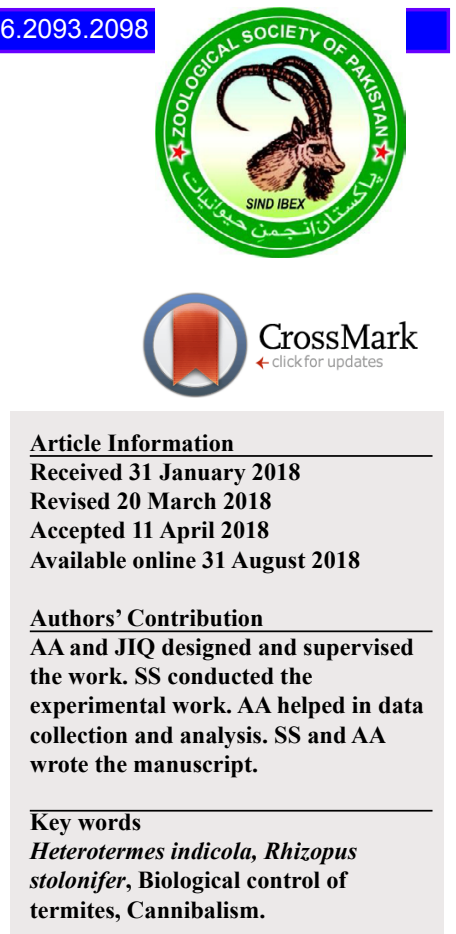

\section{INTRODUCTION}

$\mathrm{T}$ ermites are economically important insects as they cause damage to furniture, household goods, timber and forest vegetation (Aihetasham et al., 2015). In Pakistan 50 species of termites have been reported, among which Heterotermes indicola (Wasmann) is the most common, problematic pest, abundantly found all the around year and is well known as wood destroyer in urban and agricultural areas (Badshah et al., 2004a, b; Manzoor et al., 2012), causing huge losses throughout the country (Aihetasham et al., 2018).

Due to their large population and their cryptic behavior control of termites has been very challenging task. There are many ways that are practiced to control termites; these include physical, cultural, chemical, and biological methods (Wang and Powell, 2004). However, use of insecticides to control termites has produced a number of biological and environmental hazards to air, water, soil and food. Further damages include mammalian toxicology, phytotoxicology, insect outbreaks, insect resistance, pesticidal residues and increased cost of production (Zoberi, 1995; Badshah et al., 2004a, b; Saljoqi et al., 2012).

Due to the biological and environmental hazards of insecticidesresearchers'sattentionhasbeenattracted towards less toxic and safer sides of treatment. Recently practiced

\footnotetext{
* Corresponding author: qazi@scientist.com 0030-9923/2018/0006-2093 \$ 9.00/0

Copyright 2018 Zoological Society of Pakistan
}

methods which are gaining popularity are application of baits, extreme temperature, various types of barriers, asphyxiant gases and biological control (Saljoqi et al., 2012). Biological control is environment friendly measure in contrast to traditional chemical termite management. Whenever biological control is applied it has given permanent and cost effective control to particular pest population with reduced environmental hazards. Along with pest control in select situation it gives knowledge to the importance of naturally occurring pest enemies in agricultural field (Culliney and Grace, 2000). The use entomopathogenic fungi has attracted scientists attention as an agent of biological control because of their potential to act on specific pest, wide range of hosts, harmless for other living organisms in field, similarity of environmental conditions to that of termites, self-replicating only on targeted pest, in-vitro mass production and repellent nature. Further ability to be transferred from infected to healthy termites makes them use most suitable and ideal biological control agents against termites (Zoberi, 1995; Culliney and Grace, 2000; Rath, 2000; Sun et al., 2003).

Fungus permeates into host through its cuticle, affects its metabolism by reducing its metabolites, assembling toxic products and wastes, disintegration of essential tissues or aggregation of all three aspects. Generally conidial attachment occurs on integument's surface of insect where it grows and diffuses into the integument. Here it grows in haemocoel and produces toxins ultimately resulting to the insect's mortality. Anyhow there is possibility for some fungal spp. to infest termite via alimentary canal. Germination occurs in foregut and invades into foregut 
cuticle developing into hyphal bodies in haemocoel. The viability of conidia decreases through oral ingestion reducing pathogenicity of fungus whereas conidial or hyphal extracts of fungus are reported to contain toxicants which, when ingested, may reduce activities of termite such as feeding, tunneling and aggressive behavior and even may cause death of host in severe cases (Rath, 2000; Verma et al., 2009). Termites may show several behavioral responses resulting into avoidance of fungus such as burial of infected cadavers before sporulation, sealing of walls or cadavers to minimize contact transfer, grooming behavior and repellency. In addition to the behavioral defenses feces of termite also harbor antifungal properties thus presence of fecal pellet material significantly decrease the germination rate of spores (Rosengaus et al., 1998). Enclosing spores in fecal matter reduces the fungal spores germination potential. Individually immunological response may arise within termites as a defense to fungal attack (Rath, 2000; Chouvenc et al., 2009).

Virulence of fungal strain, physiological characteristics like production of enzyme, sporulation time, viability of conidia, germination speed, growth rate of hyphae, conidia production and environmental factors influence the results of their application (Sun et al., 2003; Hoe et al., 2009). Consequences of these factors may influence the efficacy of the isolate which must be taken into account to reproduce best results. Pathogenicity of the strain may vary from host to host due to differences in ability of fungal cuticle invasion and response of affected insects towards relative attack. Therefore it has been suggested to isolate fungi from naturally infested termite for best results of their application as a biological control agent (Verma et al., 2009).

The present research aimed at the isolation of fungus from cadavers of $H$. indicola and to verify potential of fungal isolate to cause epizootics mediated mortality in the same species of termite. Suitable time exposure for effective application of eco-friendly bio-insecticide targeting $H$. indicola is reported in this communication and suggestions are made for further investigation for more promising results.

\section{MATERIALS AND METHODS}

\section{Collection of termites}

Subterranean termite, $H$. indicola was collected from dead as well as living infested woods from different areas of Lahore, Pakistan. Healthy and mature workers were isolated and for bioassay maintained at $26 \pm 2^{\circ} \mathrm{C}$.

\section{Fungal isolation}

One hundred termites $(H$. indicola $)$ were placed in a petri plate equipped with moisten tissue paper and a small moist ball of cotton. The plate was covered, wrapped in black cloth and left on at room temperature. The plate was checked daily to maintain humidity until fungus appeared on dead termites. Then conidia were picked from grown fungus on dead termites under aseptic conditions and loop was then touched on Sabouraud dextrose agar yeast (SDAY) medium at its center and the plate was incubated at $28^{\circ} \mathrm{C}$ for $3-4$ days. Sample was purified by inoculating spores repeatedly on SDAY until single strain was obtained.

\section{Fungus identification}

Fungus was identified by utilizing slide culture method (Johnson, 1946) following incubation of the slide at $28^{\circ} \mathrm{C}$, confirmed by the Department of Botany, University of the Punjab, Lahore. The growth was stained with methylene blue and examined under microscope for morphological features.

\section{Mortality and feeding test}

Three day old fungal culture grown on SDAY media was taken in 6 sets of petri plates and each set comprised three replicates. Set 7 was kept as control. Three hundred workers of $H$. indicola were released in each fungal experimental plate for different time intervals. Workers in each set from 1 to 6 were exposed to fungal culture for $10,15,20,30,45$ and $60 \mathrm{~min}$. Thus treated workers were then transferred into pre-sterilized plates with moisten preweighed filter paper and kept at $26 \pm 2^{\circ} \mathrm{C}$. Dead termites were counted and removed daily and the readings were taken up to 31 days. At end of the experiment filter papers were again weighed.

\section{Repellency test}

Clean petri-plates were taken and incubated for $2 \mathrm{~h}$ at $100^{\circ} \mathrm{C}$. After that circular filter paper of the size of petri-plate. The filter paper was cut at its diameter into two pieces and placed in petri-plates. One half was moistened by distilled water and the other half by conidial suspension, made by dissolving $100 \mu 1$ of conidia in $100 \mathrm{ml}$ distilled water in a ratio of 1:1000. Ten termite's workers were released in the center of petri-plates. Three replicates were prepared. After that the plates were covered with black cloth to provide dark condition and kept at $\pm 28^{\circ} \mathrm{C}$.

A treatment concentration was considered repellent when 21 (sum of three replicates) of 30 termites were present on untreated filter paper (Aihetasham et al., 2017). Five readings were taken to count the number of workers for each piece of filter paper after every $15 \mathrm{~min}$.

\section{Statistical analysis}

Data collected were statistically analyzed by one factor ANOVA test on excel file. 


\section{RESULTS}

\section{Isolation and morphological identification}

A single strain of fungus isolated from dead $H$. indicola (workers) was identified as Rhizopus stolonifer on the basis of general morphological characters. Cultural characteristics included: mycelia gave cottony appearance initially radiated erect and gradually forming complex texture. Blackish conidia became visible after $72 \mathrm{~h}$ of incubation and their density increased at increasing incubation time. Higher density of conidia was observed on periphery of the plate than at center. Stolons of fresh culture of $R$. stolonifer were white but as culture grew older they turned brownish in color. Microscopic observations of $R$. stolonifer revealed its hyphae to be very complex, branched, multi-nucleated and lack segmentation, presence of well-developed rhizoids, unbranched sporangium supported by stalk and zygospore's formation further helped in identification of the fungus.

Anti-termitic activity of $\mathrm{R}$. stolonifer on $\mathrm{H}$. indicola

Anti-termitic activity of $R$. stolonifer to $H$. indicola was assessed by 46.11, 62.44, 77.00, 63.00, 52.44 and $40.89 \%$, mortalities of the workers exposed for $10,15,20$, 30,45 and $60 \mathrm{~min}$, respectively, after one month. Whereas percentage mortality for control workers observed was $3.33 \%$ throughout the experimental observational period (Fig. 1). Mortalities of fungus exposed termites exhibited a parabolic trend for the exposure time with statistically significant variations $(\mathrm{P}<0.05)$ (Suplementary Table I).

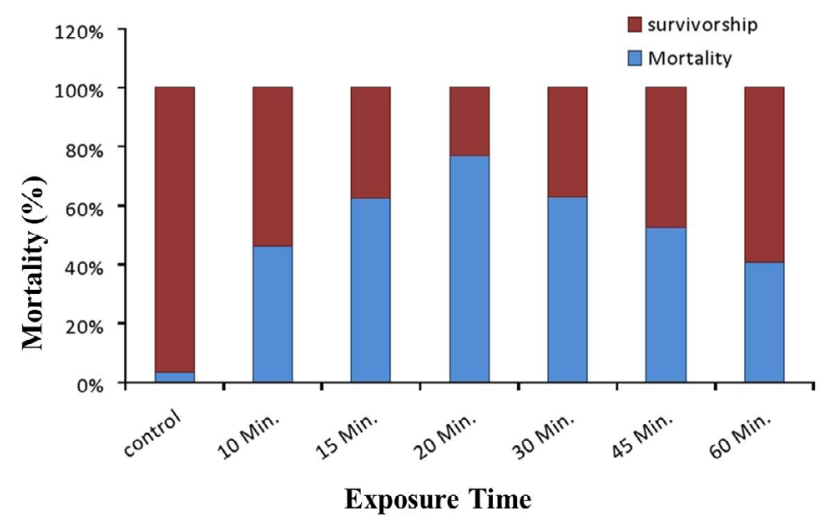

Fig. 1. Effect of exposure of Heterotermes indicola and Rhyzopus stolonifera for different time periods (10-60 $\min$ ) on its morality.

\section{Food consumption}

Food consumption was assessed by measuring weight of filter paper before and at termination of an experiment. The control workers, consumed food up to $253 \mathrm{mg}$, whereas following $10,15,20,30,45$ and $60 \mathrm{~min}$ and month's exposure to the $R$. Stolonifer the food consumption decreased down to $156,183,110,200,130$ and $143.33 \mathrm{mg}$, respectively (Table I). Decline in feeding behavior was observed amongst the fungal exposed termites statistically nonsignificant $(\mathrm{P}>0.05)$ (Suplementary Table I).

Table I.- Effect of Rhyzopus stolonifer on the mortality, feeding and behavioral changes (cannibalism) of $\boldsymbol{H}$. indicola after 31 days. Values are Mean \pm SEM.

\begin{tabular}{lccc}
\hline & $\begin{array}{c}\text { Mortality } \\
(\mathbf{X} \pm \text { SEM) }\end{array}$ & $\begin{array}{c}\text { Feeding } \\
(\mathbf{m g} \pm \text { SEM })\end{array}$ & $\begin{array}{c}\text { Cannibalism } \\
(\mathbf{X} \pm \text { SEM })\end{array}$ \\
\hline Control & $10 \pm 2.0$ & $253 \pm 24.04$ & $0 \pm 0$ \\
$10 \mathrm{~min}$ & $138.33 \pm 26.82$ & $156.67 \pm 68.87$ & $100.33 \pm 10.48$ \\
$15 \mathrm{~min}$ & $187.33 \pm 31.8$ & $183.33 \pm 53.64$ & $42 \pm 10.78$ \\
$20 \mathrm{~min}$ & $231 \pm 41.67$ & $110 \pm 46.19$ & $24.33 \pm 10.79$ \\
$30 \mathrm{~min}$ & $189 \pm 32.32$ & $200 \pm 90.73$ & $46.67 \pm 18.31$ \\
$45 \mathrm{~min}$ & $157.33 \pm 71.37$ & $130 \pm 63.50$ & $69 \pm 49.09$ \\
$60 \mathrm{~min}$ & $122.67 \pm 15.37$ & $143.33 \pm 34.80$ & $58.67 \pm 4.80$ \\
\hline
\end{tabular}

\section{Cannibalism}

Broken head and abdominal body parts were seen in experimental plates. Up to $33.44,14,8.11,15.55,23$ and $19.55 \%$ of cannibalized termites were observed following $10,15,20,30,45$ and 60 min during month time fungal exposure, respectively. Whereas, no cannibalism was observed in control plates. Significant increase observed in extent of cannibalism was corresponding to increase in exposure time $(\mathrm{P}<0.05)$ (Suplementary Table I).

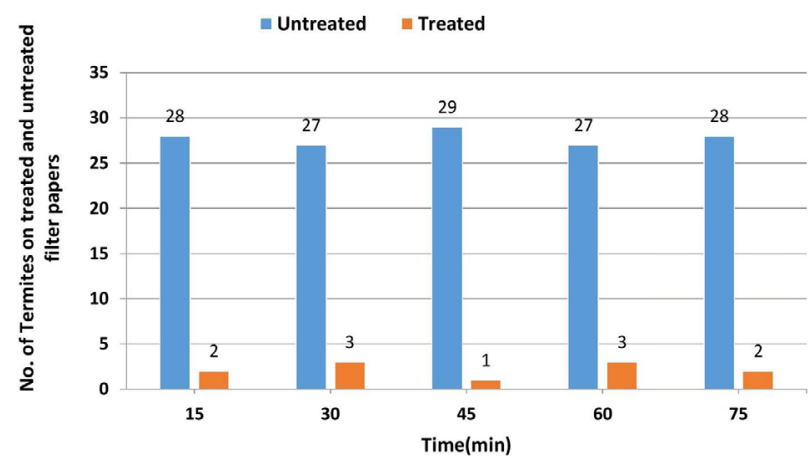

Fig. 2. Repellency test of Rhyzopus stolonifera conidia against Heterotermes indicola $(\mathrm{n}=30)$.

\section{Repellency test}

Presence of conidial suspension of $R$. stolonifer on filter paper acted as potent repellent to the workers of $H$. indicola (Fig. 2; Table II). 
Table II.- Repellency test for $\boldsymbol{R}$. stolonifer against $\boldsymbol{H}$. indicola.

\begin{tabular}{lcc}
\hline Time & $\begin{array}{c}\text { Conidial dilution } \\
\text { (No. of termites) }\end{array}$ & $\begin{array}{c}\text { Distilled water } \\
\text { (No. of termites) }\end{array}$ \\
\hline 15 min & 2 & 28 \\
$30 \mathrm{~min}$ & 3 & 27 \\
$45 \mathrm{~min}$ & 1 & 29 \\
$60 \mathrm{~min}$ & 3 & 27 \\
$75 \mathrm{~min}$ & 2 & 28 \\
\hline
\end{tabular}

\section{DISCUSSION}

Results of the present study revealed association of Rhizopus stolonifer, as the fungus was isolated from dead specimens. Zoberi and Grace (1990) described association of $R$. stolonifer to Reticulitermes flavipes (Isoptera: Rhinotermitidae) as opportunistic pathogen. In another survey, $R$. stolonifer has also been reported as detrimental to sunn pest (Eurygaster integriceps) (Assaf et al., 2011).

Isolated strain of $R$. stolonifer was not highly virulent to $H$. indicola, as highest mortality $(77.00 \%)$ was recorded after a month to fungal exposure. However, for control experiment only $3.33 \%$ mortality was recorded. High virulence may have many advantages but with respect to transmission it may not be beneficial as termites that are not intensely infected live longer and therefore provide greater opportunity to spread spores by horizontal transmission (Kramm et al., 1982).

Mortalities (\%) gradually increased responding to increases in the exposure time and then decreased for further exposure displaying parabolic trend. Our results contradict to the results of Khan et al. (2009) who reported that pathogenicity of $A$. flavus against three termite species (H. indicola, B. beesoni and M. championi) by surface culture method showed high mortality when the tested organism was left for longer time. In the present study it was observed that the fungus complex hyphal structure turned into conidiospores with 4 days within experimental plates. As the conidiospores are not actively metabolizing structure, it appears plausible to speculate that antitermite chemical production and their secretion might be higher at pre-conidial stage. Accordingly a parabolic trend of mortalities for the exposure time was observed. These results indicate importance of proper stage of opportunistic pathogen to exert detrimental effects on one hand. And on the other hand dictate for identification of proper time frame at which maximum extraction of best controlling biotic components can be extracted from fungal culture for different applications. Further studies correlating potential production of antitermite agents at particular stage of fungal development are very imperative.

Food consumption reduced in infected termites as compared to the control workers. The fungus was found a potent repellent for the workers of $H$. indicola. Our results are supported by the work of Sun et al. (2008), in which different concentrations of Metrarhizium anisopliae mixed with mulches were used against $C$. formosanus. Foragers were significantly repelled and there was remarkable reduced food consumption.

Grooming behavior is commonly seen in termites, in order to get rid of microbial contamination over cuticle. This act may be conducted as pathogen preventive measure to reduce the occurrence of epizootics (Rath, 2000). However, in course of grooming behavior lethargic and heavily infected termites get bitten up, buried in filter paper residues and cannibalized by their nest mates. Yanagawa et al. (2011) also documented comparable results while studying the pathogen-prevention behavior of $C$. formosanus. The termites treated with fungi of different virulences were mixed with untreated termites. The inoculated termites were attacked, eaten up and buried by healthy termites. These results suggested that virulence of fungal strains do not influence on termite behavior, whereas different isolates and genera of fungi influence horizontal transmission pattern, mortality and survivorship differently.

In spite of successful reproducible results (Rosengaus and Traniella, 1997; Kramm et al., 1982; Wang and Powell, 2004; Chouvenc et al., 2009) fungal control is not fruitful in fields (Rath, 2000). Despite of the fact that soil harbors fungal spores but still there is no evidence of natural out break for fungal infection in any termite nest. There may be many factors involved to the downfall of the fungal control: presence of millions of termites foraging deep down in complex galleries controlling microenvironment of the galleries by fluctuating humidity, temperature, carbon dioxide and naphthalene that may inhibit fungal growth (Wang and Powell, 2004). Failing of "trap and treat" strategy may be due to release of very low number of infected termites in contrast to very large colony in field. By releasing increased number of infected termites and effective penetrating system may help in outburst of epizootics (Hussain and Tian, 2013). On the other hand, defensive behavior displayed by termites such as avoidance to the biopesticide source (Hussain and Tian, 2013), burial of infected termites (Kramm et al., 1982), sealing off the walls of infected termites are (Staples and Milner, 2000), grooming behavior (Rath, 2000; Yanagawa et al., 2009) and of fecal pellet of termites antifungal characteristics (Rosengaus et al., 1998) are to be taken into account while designing biological control strategies. Thus a lot of work would be required to develop effective system that makes 
fungal control applicable in field.

If all aspects of our strain are correlated it gives a very good opportunity for further studies to control damages caused by termites in agriculture as well as in urban areas.

The present $R$. stolonifer is potent repellent, induces reduction in food consumption, provoke cannibalism and being less virulent it provides higher opportunity for horizontal transmission and cause mortality. The characteristics make the fungus an ideal potent agent for the development of mycoinsecticide in order to promote targeted pest control approach without any harmful effects on environment and also to promote its applications in integration with slow acting insecticide for effective termite management.

\section{Supplementary material}

There is supplementary material associated with this article. Access the material online at: http://dx.doi. org/10.17582/journal.pjz/2018.50.6.2093.2098

\section{Statement of conflict of interest}

Authors have declared no conflict of interest.

\section{REFERENCES}

Aihetasham, A., Akhtar, M.S., Umer, M., Rasib, K.Z. and Din, M.I., 2017. Bioactivity of extracts of Foeniculum vulgare and Ocimum basilicum against Heterotermes indicola (Wasmann). Pakistan J. Zool., 49: 2193-2199. https://doi.org/10.17582/ journal.pjz/2017.49.6.2193.2199

Aihetasham, A., Qayyum, F. and Xaaceph, M., 2015. Pathogenicity of Aspergillus parasiticus against Coptotermes heimi (Wasmann). Punjab Univ. J. Zool., 30: 51-55.

Aihetasham, A., Aziz, H. and Rasib, K.Z., 2018. Efficacy of slow acting toxicants on Heterotermes indicola (Wasmann) (Isoptera: Rhinotermitidae). Pakistan J. Zool., 50: 373-375. http://dx.doi. org/10.17582/journal.pjz/2018.50.1.sc3

Assaf, L.H., Haleem, R.A. and Abdullah, S.K., 2011. Association of entomopathogenic and other opportunistic fungi with insects in dormant locations. Jordan J. biol. Sci., 4: 87-92.

Badshah, H., Ullah, F., Salihah, Z., Farid, A. and Saljoqi, A.U.R., 2004a. Efficacy of mercuric chloride and copper sulphate against termites (Heterotermes indicola) (Isoptera: Rhinotermitidae). Sarhad J. Agric., 20: 275-278.

Badshah, H., Farmanullah., Salihah, Z., Saljoqi, A.U.R. and Shakur, M., 2004b. Toxic effects of AK (Calotrpis procera) plant extract against termites
(Heterotermes indicola and Coptotermes heimi) Isoptera: Rhinotermitidae. Pakistan J. biol. Sci., 7: 1603-1606.

Chouvenc, T., Su, N.Y. and Robert, A., 2009. Cellular encapsulation in the eastern subterranean termite, Reticulitermes flavipes (Isoptera), against infection by the entomopathogenic fungus Metarhizium anisopliae. J. Inverteb. Pathol., 101: 234-241. https://doi.org/10.1016/j.jip.2009.05.008

Culliney, T.W. and Grace, J.K., 2000. Prospects for the biological control of subterranean termites (Isoptera: Rhinotermitidae), with special reference to Coptotermes formosanus. Bull. entomol. Res., 90 : 9-22. https://doi.org/10.1017/S0007485300000663

Hoe, P.K., Bong, C.F.J., Jugah, K. and Rajan, A., 2009. Evaluation of Metarhizium anisopliae var. anisopliae (Deuteromycotina: Hyphomycete) isolates and their effects on subterranean termite Coptotermes curvignathus (Isoptera: Rhinotermitidae). Am. J. Agric. biol. Sci., 4: 289297. https://doi.org/10.3844/ajabssp.2009.289.297

Hussain, A. and Tian, M.Y., 2013. Germination pattern and inoculum transfer of entomopathogenic fungi and their role in disease resistance among Coptotermes formosanus (Isoptera: Rhinotermitidae). Int. J. Agric. Biol., 15: 319-324.

Johnson, E.A., 1946. An improved slide culture technique for the study and identification of pathogenic fungi. J. Bacteriol., 51: 689-694.

Khan, K.I., Jafri, R.H. and Ahmad, M., 2009. Pathogenicity and development of Aspergillus flavus in various species of termites. Punjab Univ. J. Zool., 24: 1-18.

Kramm, K.R., West, D.F. and Rockenbach, P.G., 1982. Termite pathogens: Transfer of the entomopathogen Metarhizium anisopliae between Reticulitermites sp. termites. J. Inverteb. Pathol., 40: 1-6. https:// doi.org/10.1016/0022-2011(82)90029-5

Manzoor, F., Sayyed, A.H., Rafique, T. and Malik, S.A., 2012. Toxicity and repellency of different insecticides against Heterotermes indicola (Isoptera: Rhinotermitidae). J. Anim. Pl. Sci., 22: 65-71.

Rath, A.C., 2000. The use of entomopathogenic fungi for control of termites. Biocont. Sci. Technol., 10: 563581. https://doi.org/10.1080/095831500750016370

Rosengaus, R.B. and Traniello, J.F.A., 1997. Pathobiology and disease transmission in Dampwod termites [Zootermopsis angusticollis (Isoptera: Termopsidae)] infected with the fungus Metarhizium anisopliae (Deuteromycotina: Hyphomycetes). Sociobiology, 30: 185-195. 
Rosengaus, R.B., Guldin, M.R. and Traniello, J.F.A., 1998. Inhibitory effect of termite fecal pellets on fungal spore germination. J. chem. Ecol., 24: 16971706. https://doi.org/10.1023/A:1020872729671

Saljoqi, A., Khan, M.A., Huma, Z., Sattar, A., Ullah, M. and Khan, F., 2012. Behavioral changes of Heterotermes indicola (Isoptera: Rhinotermitidae) against some natural products. Pakistan J. Zool., 44: 1613-1622.

Staples, J.A. and Milner, R.J., 2000. A laboratory evaluation of the repellency of Metarhizium anisopliae conidia to Coptotermes lacteus (Isoptera: Rhinotermitdae). Sociobiology, 36: 133-146.

Sun, J.Z., Fuxa, J.R., Richter, A. and Ring, D., 2008. Interactions of Metarhizium anisopliae and tree-based mulches in repellency and mycoses Against Coptotermes formosanus (Isoptera: Rhinotermitidae). Environ. Ent., 37: 755-763. https://doi.org/10.1093/ee/37.3.755

Sun, J., Fuxa, J.R. and Henderson, G., 2003. Effects of virulence, sporulation, and temperature on Metarhizium anisopliae and Beauveria bassiana laboratory transmission in Coptotermes formosanus. J. Inverteb. Pathol., 84: 38-46. https:// doi.org/10.1016/S0022-2011(03)00122-8

Verma, M., Sharma, S. and Prasad, R., 2009. Biological alternatives for termite control: A review. Int.
Biodeter. Biodegr., 63: 959-972. https://doi. org/10.1016/j.ibiod.2009.05.009

Wang, C. and Powell, J.E., 2004. Cellulose bait improves the effectiveness of Metarhizium anisopliae as a microbial control of termites (Isoptera: Rhinotermitidae). Biol. Contr., 30: 523-529. https:// doi.org/10.1016/j.biocontrol.2004.02.007

Yanagawa, A., Fujiwara-Tsujii, N., Akino, T., Yanagawa, T. and Shimizu, S., 2011. Behavioral changes in the termite, Coptotermes formosanus (Isoptera), inoculated with six fungal isolates. J. Inverteb. Pathol., 107: 100-106. https://doi.org/10.1016/j. jip.2011.03.003

Yanagawa, A., Yokohari, F. and Shimizu, S., 2009. The role of antennae in removing entomopathogenic fungi from cuticle of the termite, Coptotermes formosanus. J. Insect Sci., 9: 1-9. https://doi. org/10.1673/031.009.0601

Zoberi, M.H., and Grace, J.K., 1990. Fungi associated with the subterranean termite Reticulitermes flavipes in Ontario. Mycologia, 82: 289-294. https:// doi.org/10.2307/3759899

Zoberi, M.H., 1995. Metarhizium anisopliae, a fungal pathogen of Reticulitermes flavipes (Isoptera: Rhinotermitidae). Mycologia, 87: 354-359. https:// doi.org/10.2307/3760831 